\title{
Call Admission Control in HAP W-CDMA Cellular Systems
}

\author{
Behnaz Behzadi \\ Faculty of Engineering, Islamic Azad University, South Branch, Tehran, Iran \\ Email: Behnaz_behzadi2003@yahoo.com
}

Received June 15, 2013; revised July 15, 2013; accepted July 25, 2013

Copyright (C) 2013 Behnaz Behzadi. This is an open access article distributed under the Creative Commons Attribution License, which permits unrestricted use, distribution, and reproduction in any medium, provided the original work is properly cited.

\begin{abstract}
Among various radio sources which control different dependencies/functions, in this article, we will talk about the Call Admission Control (CAC), and we are supposed to confine our concentration on W-CDMA which is based on high raised platforms, since during the recent years remarkable amount of attention has been focused on platforms located in stratosphere layer [1]. Firstly, we study the capacity of uplink from HAP (High Altitude Platform) W-CDMA and we'll work on estimation and power control defects in a new conversation added to current conversations. We'll enhance the Call Admission Control (CAC) based on the side effects of power control defects and users' stimulus and then compare the CAC which has been measured by using of momentary energy on bit in the spectral density form $\left(E_{b} / N_{0}\right)$. Then we examine the mentioned charts for two different criteria which the decision will be made by these criteria in order to decide if exchanged calls are to be admitted or not. The first criterion is based on the minimum of $\left(E_{b} / N_{0}\right)$ of the first row cells meanwhile the second criterion is based on the average of $\left(E_{b} / N_{0}\right)$ of first row-cells.
\end{abstract}

Keywords: High Raised Platforms; Call Admission Control; Quality of Services; Power Control Defects

\section{Introduction}

The HAPS internal potentials will be appeared gradually, HAPS (High Altitude Platform Station) is the name of a technology which provides far distance communication between wide and narrow fiber.

The aim of HAPS is to offer the services to the users using planes with pilot or none pilot running planes, or balloons. These platforms are available for several usages and will be used in estratosphery zone in the height range of $20-50 \mathrm{~km} \mathrm{[2].}$

It's not a cutting-edge innovation to use platforms as a none-polluter and cheap and flexible. These platforms can be accordant with satellite and also earth-established equipments since they can be an organizer as a foundation. Also HAPS can be used in a special event such as Olympics to be covered when there'll be lots of crowd.

Daily enhancement of demands for telecommunication systems and having new systems with a wide range of fibers has turned the trend to the use of more high-tech systems to meet the demand. The third generation of mobile cellular telecommunication and the following generation have been designed in a wide telecommunication and several sided accessibility with pass code, plus having more capacity in comparison with current systems, to be able to provide a sending with different rates.

This paper investigates a HAP W-CDMA cellular system based on a high platform. One of the radio sources that controls the HAP W-CDMA system's functions. In this article, we concentrate on call admission control which it means to admit or to reject a call will be admited when it receives the service quality from the net and no good to be mentioned that this issue will affect on call service quality that is being used. At the same time, it's possible that QoS rejects the current calls.

Lots of issues are engaged in call admission but the power control is above the qualification and possibility. In real systems, the control defects power will lead to some alterations in receiving power by a central station which consequently lead to some alterations in ratio of receiving energy per bit to spectral density of powernoise of $\left(E_{b} / N_{0}\right)$. Call admission will be done based on measures of $\left(E_{b} / N_{0}\right)$. Two thresholds will be considered for new transferred calls and exchanged calls.

The process will be as below in the second ward. We will analyze the call admission control. The third part contains an explanation of the offering plan and laying matters. In the forth part, the simulated results have been offered and the point of discussion. And lastly, the result 
and observations are in the fifth section.

\section{Review on Call Admission Control Performance}

Considering the advantages of this crucial talk, the call admission control charts are the point of this research. In this part, we will specify the prominent features of CDMA. Our study is based on linear alterations of time field [3-6].

The all CAC can't cease the power control defects and according to studies, receiving power by each central station from a user is stable and equal to other users. In spite of this, practical power control defects lead to alterations in receiving power which cause the net function to get worse [2,7].

Signal to-interference ratio (SIR) is one of the effective parameters in QoS in each telecommunication and communication system. In CDMA systems, the SID measuring can promote function of CAC by predicting the effect of each new call on current call quality in the same or neighboring cells. All the CAC measuring SIR is estimated considering that power control is completed. But in authentic systems power control defects will increase the doubts about the function. We are going to compare the result of the both CAC with completed power control and defects considering CAC. So we illustrate the effects of power control on system function.

\section{Offering Plan for Call Admission Control}

In this article, we analyze the $\mathrm{CAC}$ which is based on the average management concept in a short period of time which will be done in average SIR estimation of current calls in order to decline any possible fault. Then we compare the out coming results with completed power control. We will estimate this in a cellar system HAPWCDMA with multi-functional service, one of the most noticeable advantages of such systems is flexibility, reconstruction features, cheap practicality, having low radiation delay, extended covering [1].

\section{Designing the Parameters}

In this study, we consider a HAP in the height of $20 \mathrm{~km}$ with an antenna having fuzzy arrays based on ITU Theory (Equation (1)) [8].

$$
G(\vartheta)= \begin{cases}34.8-3\left(\frac{\vartheta}{1.57}\right)^{2}, & \text { for } 0^{\circ} \leq \vartheta \leq 4.53^{\circ} \\ 9.8, & \text { for } 4.53^{\circ}<\vartheta \leq 5.87^{\circ} \\ 55.95-60 \log (\vartheta), & \text { for } 5.87^{\circ}<\vartheta \leq 37^{\circ} \\ -38.2, & \text { for } 37^{\circ}<\vartheta \leq 90^{\circ}\end{cases}
$$

The cell radius will be selected in a way that the gain in edges of cell to be $10 \mathrm{~dB}$ less than the maximum gain. In our study, we investigate a group of services which their specifications are as follows: (Table 1) $[9,10]$.

At first the capacity of HAP-WCDMA cellular system will be estimated based on the probability of an interruption for two states having perfect power control and defect power control. In this section, the probability of interruption will be defined considering $E_{b} / N_{0}$ being less than the needed $\left(E_{b} / N_{0}\right)$ min. There is not need to mention that the least needed energy for each bit $\left(E_{b}\right)$ in per service group will be provided based on the signal power on bit rate.

$E_{b} / N_{0}$ shows the quality as Equation (2)

$$
E_{b} / N_{0}=W / R \frac{P_{c i} e^{\alpha \theta}}{(1-\beta) \text { Iintra }+n t h}
$$

From the right order the formula represents the power of a user which has been received by a central station, although it returns back to when we consider the power control defects [11-14]. Power control defects have been considered as a long-normal distribution. So the receiving power by a station could be shown as $P_{c i} e^{\alpha \theta} \cdot P_{c i}$ defines a nominal receiving power of its class of a user by an ideal power control and $\alpha$ equals to $\frac{\ln 10}{10}$ and $\theta_{k}$ is a Gaussian random variable with zero mean and $\sigma_{p}$ represents standard deviation. $R_{b}$ is information rate and $W$ is sending band width which is equal to $5 \mathrm{MHz}$. Intercellular interference (Iintra) is originated from the interference between users which are located in the same cell. $\beta$ will show the performance of the central station with multiuser clarifying. nth is the power of thermal noise. The performance of multiuser clarifying method is percentage of Iintra which in this paper $\beta$ will be equal to zero. Also we assume $\frac{P_{c 1}}{n t h}=-1 \mathrm{~dB}$ All the interfering signals are under the effect of power control with same statistical specification of any signal.

$$
\text { Iintra }=\sum_{i=1}^{M 10} P_{c 1} e^{\alpha \theta}
$$

$M 10$ is the number of user of group 1 which are effective on cellular interference. Receiving power from the user hasn't been considered. Considering the users distributions, we imagine we would have equal distribution in each cell. Also the number of users has a poison distribution.

Table 1. Service class specifications.

\begin{tabular}{cccc}
\hline $\begin{array}{c}\text { Information } \\
\text { bitrate }\end{array}$ & $\begin{array}{c}\text { Minimum } \\
\text { required } E_{b} / N_{0}\end{array}$ & $\begin{array}{c}\text { Power } \\
\text { factor }\end{array}$ & $\begin{array}{c}\text { Typical } \\
\text { applications }\end{array}$ \\
\hline $12.2 \mathrm{~kb} / \mathrm{s}$ & $5 \mathrm{~dB}$ & $0 \mathrm{~dB}$ & Voice \\
\hline
\end{tabular}




$$
P_{n}(n)=e^{-\lambda} \frac{\lambda^{n}}{n !}
$$

$\lambda$ is the average users in each cell. So by this formula the number of users in each cell depends on the number of users in others. The average of $E_{b} / N_{0}$ will be taken for each cell and group-service and will be recorded for each $2.5 \mathrm{~S}$ on $E_{b} / N_{0}$. With any new call demand or transferred calls these measures will be compared with predefined threshold [2].

Here we simulate for a 2-second period of time, with having mostly 8 saved measures. Receiving a new call or a transferred call request is based on the average of $E_{b} / N_{0}$ and will be counted by the average of 8 saved equivalent values. This method will be done both for nominated cell to be used for call service and the first-row cells [15].

Based on the average value of $E_{b} / N_{0}$ cells of the first row should be in a way to provide the quality of current calls and to ensure that a new call in its first try won't fail. In our method, all the first-row cells should specify the whole admitting criteria since now on. We refer to minimum maker criteria which are the items that count the least average of $E_{b} / N_{0}$ of first-row cells for each service group and compare it with predefined thresholds. In other words, the algorithm calculates average of $E_{b} / N_{0}$ for each groupservice in each cell and selects the smallest value. In the suggested algorithm, transferred calls are in higher priority rather than new calls in which the smaller levels are for transferred calls and bigger ones are for call requests.

Table 2 shows the CAC parameters. The aim of choosing the appropriate measurements for threshold levels is to make the possible interruption of each service group like a reasonable one. The values of these threshold levels are greater than minimum of required $E_{b} / N_{0}$.

So our suggested model is as follows: measurement of $E_{b} / N_{0}$ should be done each $2.5 \mathrm{~S}$. A new call request or an already received transferred call measures the amount for nominated cells for service and the first-row cells which are to be average. This measurement gives two values as result. The first one is the average of $E_{b} / N_{0}$ for each service group in selected cells to service the calls and the second one is the average of $E_{b} / N_{0}$ for each service in first-row cells. When we have 2 outcomes, we can use 2 approaches as: one is minimum maker and the other is average making and these 2 measurements will be compared with two predefined thresholds.

We will review four different CAC plans which have been explained as follows:

Table 2. CAC parameters.

\begin{tabular}{cc}
\hline Threshold for & $E_{b} / N_{0}$ \\
\hline New calls-same cell & $7 \mathrm{~dB}$ \\
New calls-1st tier cells & $6.7 \mathrm{~dB}$ \\
Handoff class-1 calls-same cell & $6.65 \mathrm{~dB}$ \\
Handoff class-1 calls-1st tier cells & $6.60 \mathrm{~dB}$ \\
\hline
\end{tabular}

1-AM: based on an average measurement of $E_{b} / N_{0}$ based on the least criteria.

2-IM: based on instantaneous measurement of $E_{b} / N_{0}$ based on the least criteria.

3-AA: based on an average measurement of $E_{b} / N_{0}$ based on with average criteria.

4-IA: based on instantaneous measurement of $E_{b} / N_{0}$ based on with average criteria.

\section{Simulation Environment}

Experiments in this article are done with the aim of estimating the function of defected power control in four methods of completed power control. A $4 * 4$ cellar system will be used. HAP is located directly above the 6 th cell. We are to estimate $\mathrm{n}$ unlimited net which is next to each cell in all directions of neighboring cells. A call is added to the net it's interval will be created by chart distribution in first of call the terminal's style are monotonous on simulating zone, and their direction is from to $360^{\circ}$ by chance time between two steady alterations directing toward users has a chart distribution of $40 \mathrm{~s}$. The new created direction accordant with a steady distribution is on $-45^{\circ}$ and $45^{\circ}$ to the ex-direction. And also the user pace in very first of the call is steady and will be the steady during the entire call. Simulation parameters in Table $\mathbf{3}$ are considered.

\section{Simulation Results}

We count the Grade of Service (GoS) in order to have a better parameter comparison. GoS is defined as follows:

\section{GoS $=$ Call blocking probability +10 Call dropping probability}

Figure 1 shows the Grade of Service (GoS) to the rate of incoming calls with imperfect power control with an average standard. Figure 2 shows GoS to the rate of incoming calls with imperfect power control and minimum standard and compares it with Figure 1.

\section{Conclusions}

In this paper, we propose a call admission control scheme for cellular systems HAP W-CDMA.

Funding for this project was based on measurements of $E_{b} / N_{0}$. The mechanisms used to achieve the proposed scheme provide better performance.

Parameters of the CAC, as required by the simulation

Table 3. Simulation parameters.

\begin{tabular}{cc}
\hline Parameters & Calls \\
\hline Mean call duration & $180 \mathrm{~s}$ \\
Minimum user velocity & $0 \mathrm{~m} / \mathrm{s}$ \\
Maximum user velocity & $20 \mathrm{~m} / \mathrm{s}$ \\
$\sigma_{p}$ & $1 \mathrm{~dB}$ \\
\hline
\end{tabular}




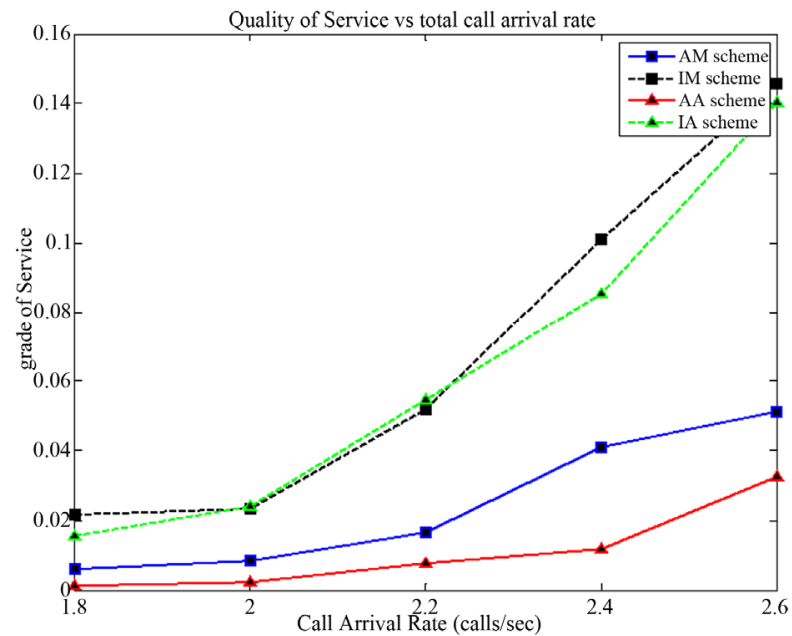

Figure 1. GoS to the rate of incoming calls with imperfect power control with average standard.

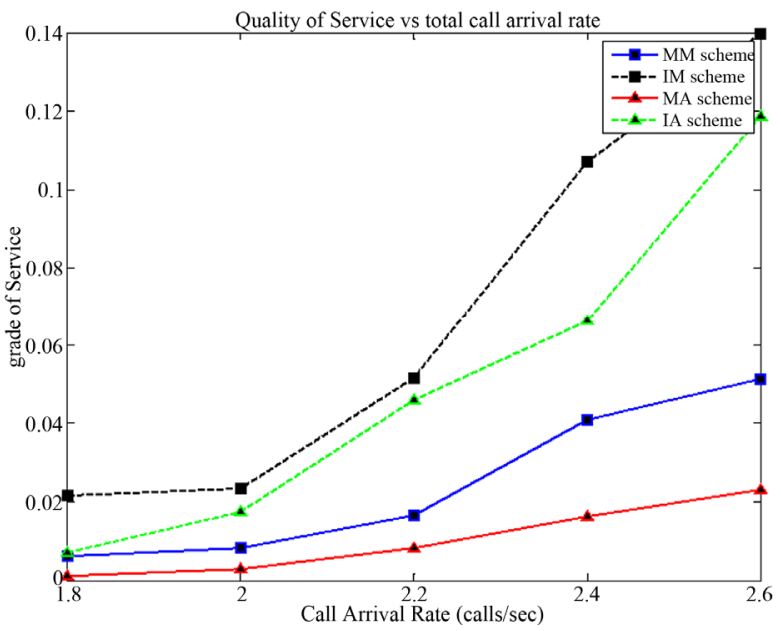

Figure 2. GoS to the rate of incoming calls with imperfect power control with minimum standard.

are chosen. In deciding whether to accept or reject calls, the proposed move of two criteria is based on the minimum and the other one is based on the average. It is based on a minimum measurement of $E_{b} / N_{0}$ and an average criteria (AA) at the lowest level of GoS. According to the results, AA is the best.

Although the hybrid schemes at HAP W-CDMA cellular system are evaluated, they can also be used as ground-CDMA systems.

\section{REFERENCES}

[1] S. Karapantazis and F.-N. Pavlidou, "Call Admission Control in Multiservice High Altitude Platform (HAP) W-CDMA Cellular Systems," Computer Networks, Vol. 51, No. 12, 2007, pp. 3491-3506. doi:10.1016/j.comnet.2007.02.003
[2] S. Karapantazis and F.-N. Pavlidou, "Broadband Communications via High-Altitude Platforms-A Survey," IEEE Communications Surveys \& Tutorials, Vol. 7, No. 1, 2005, pp. 2-31. doi:10.1109/COMST.2005.1423332

[3] S. Karapantazis and F.-N. Pavlidou, "The Role of High Altitude Platforms in beyond 3G Networks," IEEE Wireless Communications, Vol. 12, No. 6, 2005, pp. 33-41. doi:10.1109/MWC.2005.1561943

[4] Z. Liu and M. Zarki, "SIR-Based Call Admission Control for DSCDMA Cellular Systems," IEEE Journal on Selected Areas in Communications, Vol. 12, No. 4, 1994, pp. 638-644. doi:10.1109/49.286670

[5] S. Shin, C.-H. Cho and D. Sung, "Interference-Based Channel Assignment for DS-CDMA Cellular Systems," IEEE Transactions on Vehicular Technology, Vol. 48, No. 1, 1999, pp. 233-239. doi:10.1109/25.740098

[6] S. Shin and D. Sung, "DS-CDMA Reverse Link Channel Assignment Based on Interference Measurements," Electronics Letters, Vol. 31, No. 22, 1995, pp. 1897-1899. doi:10.1049/el:19951319

[7] J. M. Romero-Jerez, C. Tellez-Labao and A. Diaz-Estrella, "Effect of Power Control Imperfections on the Reverse Link of Cellular CDMA Networks under Multipath Fading," IEEE Transactions on Vehicular Technology, Vol. 53, No. 1, 2004, pp. 61-71. doi:10.1109/TVT.2003.819638

[8] ITU-R, "Minimum Performance Characteristics and Operational Conditions for High Altitude Platform Stations Providing IMT-2000 in the Bands 1885 - $1980 \mathrm{MHz}$, $2010-2025 \mathrm{MHz}$ and $2110-2170 \mathrm{MHz}$ in Regions 1 and 3 and $1885-1980 \mathrm{MHz}$ and $2110-2160 \mathrm{MHz}$ in Region 2,” Rec. ITU-R M.1456, 2000.

[9] 3GPP TS 22.105, "Services and Service Capabilities," v. 6.2.0, 2003.

[10] 3GPP TS 23.107, "Quality of Service (QoS) Concept and Architecture," v. 6.1.0, 2004.

[11] A. M. Viterbi and A. J. Viterbi, "Erlang Capacity of a Power Controlled CDMA System," IEEE Journal on Selected Areas in Communications, Vol. 11, No. 6, 1993, pp. $892-900$

[12] A. J. Viterbi and R. Padovani, "Implications of Mobile Cellular CDMA," IEEE Communications Magazine, Vol. 30, No. 12, 1992, pp. 38-41.

[13] F. D. Priscoli and F. Sestini, "Effects of Imperfect Power Control and User Mobility on a CDMA Cellular Network," IEEE Journal on Selected Areas in Communications, Vol. 14, No. 9, 1996, pp. 1809-1817.

[14] G. E. Corazza, G. D. Maio and F. Vatalaro, "CDMA Cellular Systems Performance with Fading, Shadowing, and Imperfect Power Control," IEEE Transactions on Vehicular Technology, Vol. 47, No. 2, 1998, pp. 450-459. doi:10.1109/25.669083

[15] N. Dimitriou, G. Sfikas and R. Tafazolli, "Quality of Service for Multimedia CDMA," IEEE Communications Magazine, Vol. 38, No. 7, 2000, pp. 88-94. doi:10.1109/35.852036 